Revisão / Review

\title{
Diagnóstico laboratorial da deficiência de ferro
}

\section{Laboratory diagnosis of iron deficiency anemia}

Helena Z. W. Grotto

\begin{abstract}
A deficiência de ferro é a causa mais comum de anemia e, em geral, o diagnóstico laboratorial é feito sem grandes dificuldades, usando-se testes simples e rotineiramente disponiveis pelos laboratórios em geral. A interpretação dos resultados, no entanto, deve ser feita cuidadosamente, tendo em mente as limitações e interferentes de cada reação. Nessa revisão serão apresentados os testes que auxiliam na investigação da deprivação de ferro, com algumas noções técnicas e comentários sobre a interpretação dos mesmos. Rev. Bras. Hematol. Hemoter. 2010;32(Supl.2):22-28.
\end{abstract}

Palavras-chave: Anemia ferropriva; achados laboratoriais; anemia hipocrômica.

\section{Introdução}

A deficiência de ferro é definida como a redução do ferro corpóreo total, com exaustão dos estoques e algum grau de deficiência tissular. ${ }^{1}$ Como a distribuição do ferro tem uma dinâmica própria, esse mineral pode ocupar diferentes compartimentos, que são interligados, mas que podem, didaticamente, ser avaliados separadamante. Diversos testes laboratoriais são propostos para se avaliarem esses diferentes compartimentos de ferro na investigação dos distúrbios do seu metabolismo. Esses compartimentos são: estoque, transporte e funcional, e são afetados sequencialmente à medida que o déficit de ferro corpóreo progride. Inicialmente há uma queda do ferro em estoque, seguida pela deficiência no transporte e, finalmente, redução no compartimento eritroide ou funcional. O Quadro 1 lista os testes que podem ser utilizados na investigação dos distúrbios do ferro, de acordo com o compartimento avaliado, suas vantagens e limitações.

\section{Compartimento funcional}

Compreende as medidas relacionadas à produção das hemácias de acordo com a disponibilidade de ferro para a eritropoese. a) Hemograma: dosagem de hemoglobina e valores dos índices hematimétricos. São os indicadores que primeiro sinalizam para o clínico uma possível alteração no estado do ferro. A anemia com microcitose e hipocromia $(\mathrm{VCM}<80 \mathrm{fl}$ e $\mathrm{HCM}<27 \mathrm{pg}$ ) é característica de distúrbios na fase de hemoglobinização, o que pode ser decorrente da deficiência de ferro, mas também de outras condições como hemoglobinopatias e anemia da inflamação. ${ }^{2}$ Embora a dosagem de $\mathrm{Hb}$ seja amplamente utilizada no diagnóstico das anemias, tratase de uma medida de baixas sensibilidade e especificidade quando usada isoladamente. A baixa sensibilidade é decorrente do atraso da queda dos níveis de $\mathrm{Hb}$ em relação à redução dos estoques de ferro.

Outros parâmetros constantes do hemograma seriam o RDW (red cell distribution width), que é uma medida da anisocitose e está elevado na anemia ferropriva (AF), e os parâmetros relacionados aos reticulócitos, que fornecem informações sobre o nível de atividade eritropoética da medula (será discutido posteriormente). O RDW pode auxiliar na diferenciação entre AF e $\beta$-talassemia heterozigótica, ambas anemias microcíticas. Na AF, em geral, as hemácias microcíticas variam no grau de redução do seu tamanho, conferindo um valor de RDW mais elevado do que na ß-talassemia heterozigótica, onde o grau de microcitose em

Hematologista. Professora Associada do Departamento de Patologia Clínica da Faculdade de Ciências Médicas da Unicamp - Campinas-SP. Departamento de Patologia Clínica, Faculdade de Ciências Médicas, Unicamp - Campinas-SP.

Correspondência: Helena $Z$ W Grotto

Departamento de Patologia Clínica, FCM/Unicamp - Caixa Postal 6111

Cidade Universitária Zeferino Vaz - Barão Geraldo

13083-970 - Campinas, SP - Brasil

E-mail: grotto@fcm.unicamp.br

Doi: $10.1590 /$ S1516-84842010005000046 
Quadro 1. Principais testes laboratoriais para investigação das anemias por distúrbios no metabolismo do ferro (adaptado de Cook, 2005) ${ }^{1}$

\begin{tabular}{|c|c|c|c|}
\hline Teste & $\begin{array}{l}\text { Compartimento } \\
\text { avaliado }\end{array}$ & Vantagens & Limitações \\
\hline \multicolumn{4}{|l|}{$\begin{array}{l}\text { Valores de referência } \\
\text { sugeridos }\end{array}$} \\
\hline Ferro medular & Estoque & $\begin{array}{l}\text { Bem padronizado } \\
\text { Altamente específico }\end{array}$ & Invasivo, alto custo \\
\hline $\begin{array}{c}\text { Ferritina sérica } \\
15-300 \mu \mathrm{g} / \mathrm{l} \text { (homens) } \\
15-200 \mu \mathrm{g} /(\text { (mulheres) }\end{array}$ & Estoque & $\begin{array}{l}\text { Bem padronizado } \\
\text { Custo acessível }\end{array}$ & $\begin{array}{c}\text { Sofre alterações nos processos infecciosos, } \\
\text { inflamatórios ou neoplásicos }\end{array}$ \\
\hline Transferrina sérica & Transporte & $\begin{array}{l}\text { Precisão } \\
\text { Rapidez }\end{array}$ & Não está totalmente padronizado \\
\hline $\begin{array}{c}\text { TIBC } \\
250-450 \mu \mathrm{g} / \mathrm{l}\end{array}$ & Transporte & Baixo custo & $\begin{array}{l}\text { Baixa especificidade } \\
\text { Alterado na presença de processos infecciosos e } \\
\text { inflamatórios }\end{array}$ \\
\hline $\begin{array}{c}\text { ST } \\
30 \%-45 \%\end{array}$ & Transporte & Baixo custo & Baixa especificidade \\
\hline Hemoglobina & Funcional & $\begin{array}{l}\text { Baixo custo, } \\
\text { universalmente disponível }\end{array}$ & Baixas sensibilidade e especificidade \\
\hline $\mathrm{HCM}$ & Funcional & $\begin{array}{l}\text { baixo custo, } \\
\text { universalmente disponível }\end{array}$ & $\begin{array}{c}\text { Indicador tardio } \\
\text { Baixa especificidade }\end{array}$ \\
\hline $\begin{array}{c}\text { RDW } \\
11 \%-14 \%\end{array}$ & Funcional & $\begin{array}{l}\text { Baixo custo, } \\
\text { útil no diagnóstico diferencial }\end{array}$ & $\begin{array}{c}\text { Disponibilidade limitada a determinados } \\
\text { equipamentos }\end{array}$ \\
\hline $\begin{array}{c}\text { ZPP } \\
<70 \mu \mathrm{mol} / \mathrm{mol} \text { heme }\end{array}$ & Funcional & Baixo custo & $\begin{array}{l}\text { Necessita equipamento específico } \\
\text { Sofre interferência pela exposição ao chumbo }\end{array}$ \\
\hline $\begin{array}{c}\text { Ferro sérico } \\
13-31 \mu \mathrm{mol} / / \text { (homens) } \\
12-29 \mu \mathrm{mol} /(\text { mulheres) }\end{array}$ & Funcional & Baixo custo & Baixa especificidade \\
\hline sTfR & Funcional & Não altera nas inflamações (?) & Alto custo \\
\hline $\mathrm{CHr}$, RetHe, VCMr & Funcional & $\begin{array}{l}\text { Indicadores precoces da } \\
\text { deficiência do ferro }\end{array}$ & $\begin{array}{c}\text { Estabilidade } \\
\text { Disponibilidade limitada a } \\
\text { determinados equipamentos }\end{array}$ \\
\hline $\begin{array}{l}\text { \% de hemácias } \\
\text { hipocrômicas }\end{array}$ & Funcional & Baixo custo & $\begin{array}{l}\text { Indicador precoce da deficiência de ferro } \\
\text { Disponibilidade limitada a poucos equipamentos }\end{array}$ \\
\hline
\end{tabular}

geral é maior e mais homogêneo. ${ }^{3}$ Os valores de referência vão de $11 \%$ a $14 \% .^{2}$

Sinais de deficiência na formação da Hb podem ser observados nos eritrócitos circulantes através da análise microscópica do esfregaço sanguíneo, prática que deve ser encorajada nas suspeitas de anemia, principalmente para excluir outras causas não decorrentes da deficiência de ferro. ${ }^{4}$ A Figura 1 mostra dois esfregaços de sangue de pacientes com AF (A) e com beta talassemia heterozigótica (B). Como pode ser observado, a microcitose é mais acentuada na hemoglobinopatia, enquanto a hipocromia é mais evidente na AF.

Outras alterações no hemograma que podem ser observadas nos pacientes com AF são uma contagem de leucócitos que pode estar ligeiramente diminuída, com granulocitopenia, que pode vir acompanhada de pequeno número de neutrófilos hipersegmentados. Nessa circunstância, deve ser afastada a possibilidade da associação com deficiência de folato. $\mathrm{O}$ número de plaquetas pode estar aumentado, podendo estar reduzido nos casos de anemia grave. ${ }^{5}$

$\mathrm{O}$ número de reticulócitos na $\mathrm{AF}$ em geral está normal ou reduzido. Além da contagem do número de reticulócitos em valores absolutos, o conteúdo de hemoglobina dos reticulócitos pode fornecer uma informação adicional em relação ao déficit de hemoglobinização das células e tem sido apontado como indicador precoce da deficiência de ferro. ${ }^{6}$ No Quadro 2 estão relacionadas as diferentes nomenclaturas para o parâmetro, tipo de sistema automatizado que o fornece e valores de referência sugeridos. ${ }^{7}$

b) Zincoprotoporfirina (ZPP) eritrocitária: Durante o processo da biossíntese do heme, uma redução na disponibilidade do ferro resulta no excesso de protoporfirina livre dentro da célula. $\mathrm{O}$ zinco substitui o ferro no anel de protoporfirina IX, formando o ZPP, que permanece no eritrócito e é 

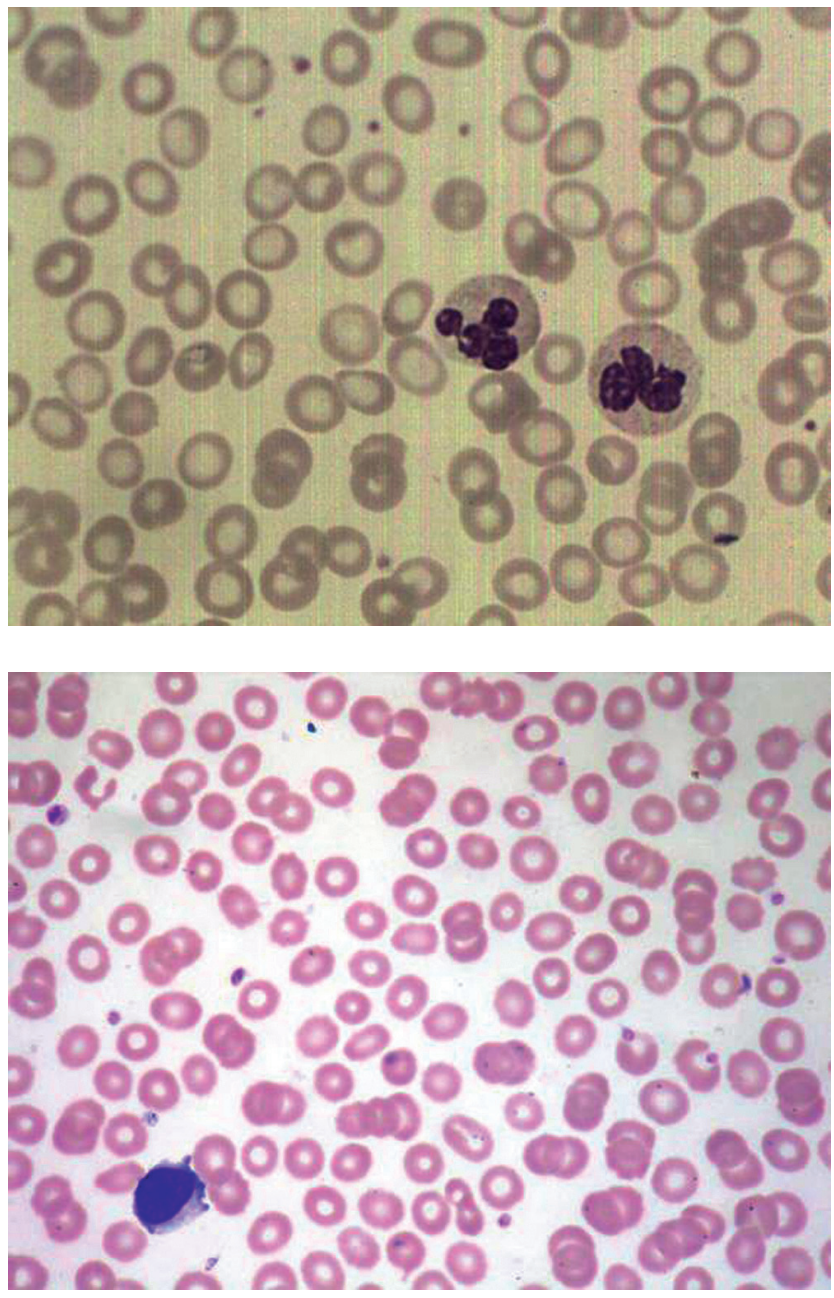

Figura 1. Microscopias de esfregaços de sangue corados com May-Grünwald-Giemsa.

A: anemia ferropriva; B: beta talassemia heterozigótica passível de medição, sendo, portanto, um indicador funcional da utilização do ferro durante o processo de maturação. O ZPP é um teste simples, usa quantidade muito pequena de sangue e pode ser medido no sangue total usando-se um hematofluorômetro. Esse teste não está ainda totalmente automatizado e consiste na colocação de uma gota de sangue numa lâmina de vidro que é inserida no instrumento e a fluorescência da ZPP é medida. A utilização de um equipamento exclusivamente direcionado para uma reação pode representar uma limitação e são poucos os laboratórios que o possuem. ${ }^{8} \mathrm{O}$ valor normal no adulto é $<80 \mu \mathrm{mol} / \mathrm{mol} \mathrm{Hb}$. Nas mulheres é um pouco mais elevado. Doenças crônicas que reduzem a concentração de ferro sérico, mas não os seus estoques, aumentam os níveis de protoporfirina. Outras causas que cursam com aumento da ZPP: envenenamento por chumbo e anemia hemolítica. ${ }^{9}$

c) Determinação do ferro sérico: $O$ ferro é transportado no plasma pela transferrina. Para determinar a concentração do ferro circulante, este deve ser dissociado da proteína transportadora pela adição de um ácido que vai precipitar a proteína. $\mathrm{O}$ ferro liberado será então quantificado pela adição de um cromógeno, resultando numa reação de cor.

A quantificação do ferro sérico está sujeita a algumas variáveis que devem ser consideradas na análise dos resultados obtidos. Essas variáveis estão relacionadas a alguns procedimentos técnicos, como contaminação durante a coleta do sangue, armazenamento ou realização do teste por resíduos metálicos, até variações fisiológicas. A concentração do ferro circulante tem um ritmo circadiano, sendo mais alta de manhã, entre 7 e 10 horas, e atingindo os menores valores perto das 21:00 horas. Essas alterações aparentemente não implicam um erro diagnóstico e não diminuem a confiabilidade do resultado. ${ }^{10}$ Por outro lado, a associação

Quadro 2. Indicadores de conteúdo de hemoglobina dos reticulócitos fornecidos por diversos sistemas automatizados, valores de normalidade sugeridos e principais aplicações clínicas ${ }^{7}$

\begin{tabular}{|c|c|c|c|}
\hline $\begin{array}{l}\text { Indicadores do conteúdo de } \\
\text { hemoglobina dos reticulócitos }\end{array}$ & Sistema & $\begin{array}{l}\text { Valores de } \\
\text { normalidade }\end{array}$ & Aplicações clínicas \\
\hline $\begin{array}{c}\text { VCMr (fl) } \\
\text { (volume corpuscular médio dos RTCs) }\end{array}$ & $\begin{array}{l}\text { Advial } \\
\text { Siemens }\end{array}$ & $\begin{array}{c}103,2-126,3^{*} \\
92,4-120,2^{* *} \\
100-114 \S \S\end{array}$ & $\begin{array}{l}\text { Valores aumentados indicam: } \\
\text { - resposta ao tratamento de AF ou com EPO } \\
\text { - atividade medular intensificada }\end{array}$ \\
\hline $\begin{array}{c}\mathrm{CHr}(\mathrm{pg}) \\
\text { (Hb corpuscular média dos RTCs) }\end{array}$ & $\begin{array}{l}\text { Advia/ } \\
\text { Siemens }\end{array}$ & $\begin{array}{l}25,9-30,6^{*} \\
27,1-33,9^{\star *}\end{array}$ & \multirow{3}{*}{$\begin{array}{l}\text { Valores diminuídos indicam: } \\
\text { - indicador precoce de deficiência de ferro, } \\
\text { ácido fólico ou vitamina B } 12 \\
\text { Outras aplicações: } \\
\text { - monitoramento da deficiência de ferro em pacientes } \\
\text { renais crônicos em tratamento com EPO } \\
\text { - preditor precoce de deficiência de ferro }\end{array}$} \\
\hline $\begin{array}{c}\mathrm{CHCMr}(\mathrm{g} / \mathrm{dl}) \\
\text { (Concentração de Hb corpuscular } \\
\text { média dos RTCs) }\end{array}$ & $\begin{array}{l}\text { Advial } \\
\text { Siemens }\end{array}$ & $\begin{array}{l}23,5-28,7^{*} \\
26,7-33,0^{\star \star}\end{array}$ & \\
\hline $\begin{array}{c}\text { Ret-He (pg) } \\
\text { (tamanho e conteúdo de Hb dos RTCs) }\end{array}$ & $\begin{array}{l}\text { Advial } \\
\text { Siemens }\end{array}$ & $\begin{array}{l}29,9-37,7^{* \star *} \\
24,1-35,8^{\star \star \star *}\end{array}$ & \\
\hline $\begin{array}{c}\mathrm{MRV}(\mathrm{fl}) \\
\text { (volume reticulocitário médio) }\end{array}$ & Horiba-Medical & $91-111 \S \S$ & $\begin{array}{l}\text { - preditor precoce da resposta ao tratamento com } \\
\text { hidroxiureia em pacientes com anemia falciforme }\end{array}$ \\
\hline $\begin{array}{c}\mathrm{MRV}(\mathrm{fl}) \\
\text { (volume reticulocitário médio) }\end{array}$ & Coulter & $\begin{array}{c}93,0-117,8 \S \\
98-120 \S \S\end{array}$ & - avaliação da administração de EPO em atletas \\
\hline
\end{tabular}

d'Onofrio et al,1995; ${ }^{* \star}$ Buttarello et al, 1995; ${ }^{* \star *}$ Canals et al, 2005); ${ }^{* \star \star * B r u g n a r a ~ e t ~ a l, ~ 2005 ; ~ § ~ B a n f i ~ e t ~ a l, ~ 2006 ; ~ § \S C a p p e l l e t t i ~ e t ~ a l, ~} 2006$ 
com determinadas condições clínicas podem interferir nos resultados, que devem ser analisados com cautela quando da presença de processos inflamatórios agudos ou crônicos, processos neoplásicos e após infarto agudo do miocárdio, situações em que os níveis de ferro sérico podem estar reduzidos. Altas concentrações são encontradas na doença hepática, anemia hipoplásica, eritropoese ineficaz e sobrecarga de ferro. ${ }^{9}$

O intervalo de referência normal depende principalmente do método utilizado e, em geral, varia entre 75 e $175 \mu \mathrm{g} / \mathrm{dL}$ (13 a $31 \mu \mathrm{mol} / \mathrm{L}$ ) em homens adultos, e aproximadamente entre 65 e $165 \mu \mathrm{g} / \mathrm{dL}(12$ a $29 \mu \mathrm{mol} / \mathrm{L})$ nas mulheres. ${ }^{11}$ A determinação do ferro sérico isoladamente é de valor limitado, devendo ser analisado em combinação com os outros parâmetros como a saturação da transferrina e ferritina sérica.

d) Receptor solúvel da transferrina (sTfR): Tem sido apontado como um bom indicador do estado do ferro funcional porque não sofre as influências sistêmicas a que estão sujeitos o ferro sérico e a ferritina, por exemplo. A síntese do sTfR é regulada pelos níveis de ferro teciduais. Durante a fase de depleção de estoques, os níveis de sTfR permanecem inalterados. Entretanto, havendo diminuição do ferro funcional há o estímulo para a síntese de TfR e os níveis de sTfR elevam-se. A determinação do sTfR pode ser realizada por testes imunoenzimáticos, como teste de ELISA, e por nefelometria. Pacientes com anemia aplásica apresentam níveis intensamente reduzidos de sTfR, compatíveis com a baixa massa de precursores eritroides na medula óssea. Indivíduos com insuficiência renal crônica podem apresentar níveis diminuídos de sTfR já que a atividade eritropoética, em geral, está reduzida devido à síntese inadequada de eritropoetina pelos rins. Valores elevados de sTfR são encontrados na deficiência de ferro e quando a atividade eritropoética está acelerada, como em diversos tipos de anemias hemolíticas hereditárias e adquiridas. Sua principal indicação é na diferenciação entre AF e anemia da inflamação (ou anemia de doença crônica) (AI), já que está elevado na $\mathrm{AF}$ e normal na AI. ${ }^{12,13,14}$ Os valores de referência variam de acordo com o método utilizado, não havendo até o momento uma padronização dos mesmos.

A relação $\mathrm{sTfR} / \log$ da ferritina é proposta por alguns autores como melhor parâmetro na diferenciação entre AF, $\mathrm{AI}$ e a combinação AF+AI, embora haja alguma sobreposição de valores na última condição clínica. ${ }^{15,16,17}$ Pacientes com depleção de estoque de ferro, acompanhada ou não de processo infeccioso/inflamatório, apresentam valores maiores dessa relação do que pacientes com anemia da inflamação com estoques de ferro repletos. ${ }^{17}$

e) Índices reticulocitários e porcentual de hemácias hipocrômicas: Alguns equipamentos hematológicos fornecem a porcentagem de eritrócitos hipocrômicos circulantes, considerados indicadores diretos da deficiência funcional de ferro. Valores reduzidos detectam a eritropoese deficiente de ferro antes do aparecimento da microcitose. Do mesmo modo, a redução do conteúdo de $\mathrm{Hb}$ nos reticulócitos precede a porcentagem de hemácias hipocrômicas e acontece poucos dias após a instalação da deficiência de ferro. Nessa fase, a eritropoese já estará comprometida, mas os níveis de $\mathrm{Hb}$ ainda estão preservados. ${ }^{18,19,20} \mathrm{O}$ uso desse parâmetro ainda está limitado a poucos sistemas automatizados

\section{Compartimento de transporte}

a) Transferrina sérica: A proteína pode ser quantificada diretamente por ensaio imunológico, como imunonefelometria. Trata-se de uma técnica rápida e precisa, mas pouco difundida entre os laboratórios clínicos e com grande variabilidade de resultados dependendo do ensaio utilizado. ${ }^{9}$

b) Capacidade total de ligação do ferro à transferrina (TIBC): É uma medida indireta da transferrina circulante.

Em $100 \mathrm{~mL}$ de soro há transferrina suficiente para se ligar a 250 a $450 \mu \mathrm{g}$ de ferro. Como a concentração normal de ferro no soro é de cerca de $100 \mu \mathrm{g} / \mathrm{L}$, normalmente a transferrina está saturada em 1/3 de sua capacidade total. Adicionandose um excesso de ferro, os sítios não ocupados (UIBC = transferrina não saturada ou capacidade latente de ocupação da transferrina) serão preenchidos e medidos. A soma do UIBC com o ferro sérico medido representa o TIBC. Na deficiência de ferro há um aumento na síntese de transferrina, cuja capacidade de ligação estará elevada. Havendo diminuição da síntese de transferrina, como acontece na vigência de um processo inflamatório, ou aumento do ferro circulante como na hemocromatose, o TIBC estará reduzido. A gravidez e o uso de anticonceptivos orais aumentam o TIBC. ${ }^{5}$

Para a obtenção do valor de TIBC a partir da transferrina sérica deve-se multiplicar o resultado da dosagem da transferrina por 25 .

c) A relação ferro sérico/TIBC fornece o índice de saturação da transferrina (ST), que é reportado em porcentagem. Normalmente esta relação é de $16 \%$ a $50 \%$. Valores inferiores a $16 \%$ são indicativos de um déficit de suprimento de ferro para o desenvolvimento das células vermelhas. A especificidade do teste é limitada, porque tanto o ferro como o TIBC tem seus valores reduzidos na inflamação. Alguns autores sugerem que a ST é mais útil na identificação da sobrecarga de ferro (ST> 55\%) do que na sua deficiência. ${ }^{8}$

\section{Compartimento de estoque}

a) Pesquisa de ferro na medula óssea: obtida através da análise de material proveniente de punção da medula óssea submetido à reação de Perl ou azul da Prússia. Grânulos de hemossiderina reagem com ferrocianeto de potássio, resultando numa coloração azulada. Os grânulos corados podem 
estar localizados dentro ou fora dos macrófagos e estarão ausentes na deficiência de ferro. ${ }^{21}$ É considerado o teste mais preciso para o diagnóstico da deficiência de ferro, mas, devido ao seu caráter invasivo e por ser desconfortável ao paciente, na prática só é realizado em casos mais complexos e não diagnosticados pelos métodos usuais. $\mathrm{O}$ resultado é dado como negativo ou de $1+$ a $5+$, sendo $2+$ considerado normal e $5+$ correspondendo a estoque de ferro marcadamente elevado. Normalmente, um pequeno número de grânulos azuis pode ser visualizado nos macrófagos. Na deficiência de ferro, esses grânulos são raros ou ausentes. Do mesmo modo, a porcentagem de sideroblastos encontra-se diminuída na AF $(<20 \%){ }^{22}$

b) Ferritina sérica: embora grandes quantidades de ferritina estejam estocadas nos tecidos do fígado e baço, somente pequenas quantidades estão presentes no soro. Essa ferritina circulante é essencialmente livre de ferro. A importância da determinação da ferritina sérica é que a sua quantificação representa uma medida precisa do ferro total do compartimento de estoque: $1 \mu \mathrm{g} / \mathrm{L}$ de ferritina sérica corresponde a $8 \mathrm{mg}-10 \mathrm{mg}$ de ferro em estoque em um indivíduo adulto. ${ }^{23}$

A concentração de ferritina circulante varia de 15 a $300 \mu \mathrm{g} / \mathrm{L}$. Os valores de normalidade são superiores nos homens ( 15 a $300 \mu \mathrm{g} / \mathrm{L})$ em relação às mulheres em idade fértil ( 15 a $200 \mu \mathrm{g} / \mathrm{L})$. Após a menopausa, esses valores são similares para ambos os sexos. ${ }^{12}$

É um teste preciso e muito utilizado para avaliar os estoques de ferro. Entretanto, por se tratar de uma proteína de fase aguda, a síntese de apoferritina está aumentada em condições inflamatórias, infecciosas e malignidade, principalmente devido ao estímulo das IL-1 e IL-6. As concentrações de ferritina sérica são particularmente influenciadas pela presença de doença hepática, como hepatite e cirrose. ${ }^{24} \mathrm{Em}$ pacientes com inflamação, infecção ou outras doenças crônicas valores inferiores a $15 \mu \mathrm{g} / \mathrm{L}$ são compatíveis com ausência de ferro no estoque e acima de $100 \mu \mathrm{g} / \mathrm{L}$ indicam a presença de estoque. Nesse grupo de indivíduos, valores de ferritina entre 15 e $100 \mu \mathrm{g} / \mathrm{L}$ devem ser interpretados com cautela porque podem ocultar uma deficiência de ferro associada. ${ }^{9}$ Estudos demonstraram que valores acima de $30 \mu \mathrm{g} / \mathrm{L}$ em pacientes anêmicos e com uma condição inflamatória associada, como artrite reumatoide ou insuficiência renal crônica, não excluem a possibilidade de uma $\mathrm{AF}$ instalada. Alguns autores sugerem que somente valores de ferritina sérica superiores a $60 \mu \mathrm{g} / \mathrm{L}$ deveriam ser considerados indicativos de estoque normal em pacientes com inflamação associada. ${ }^{25} \mathrm{Na}$ criança $(<15$ anos), valores inferiores a $12 \mu \mathrm{g} / 1$ são indicativos da deficiência de ferro. ${ }^{9}$

A deficiência de vitamina $C$ pode reduzir as concentrações de ferritina e ferro séricos. Esta, provavelmente, é a única condição em que a ferritina está reduzida na ausência de deficiência de ferro. ${ }^{26}$
Havendo sobrecarga de ferro, altas concentrações de ferritina sérica podem ser observadas, como na hemocromatose avançada, mas não nas fases iniciais, onde esses valores encontram-se normais. Doenças hematológicas malignas podem cursar com níveis elevados de ferritina e estão relacionadas com os estados de remissão e recaída da doença.

Uma causa de elevados níveis de ferritina está associada com uma síndrome hereditária caracterizada por hiperferritinemia e catarata. Descrita em 1995, ${ }^{27,28}$ tem um padrão de herança autossômica dominante e resulta de uma mutação no cromossoma $19 \mathrm{q}$, onde é codificado o gene para a subunidade $L$ da ferritina. $O$ excesso de ferritina acumula no cristalino, e a catarata torna-se sintomática, em geral a partir da segunda década de vida. O ferro sérico e o TIBC encontramse em níveis normais.

Os métodos para determinação da ferritina sérica atualmente utilizados são imunoenzimáticos, utilizando anticorpos antiferritina humana, através de técnicas de ELISA ou eletroquimioluminescência, disponibilizados em kits comerciais. A automatização dessas técnicas tem assegurado resultados confiáveis e rápidos a um custo bastante razoável. ${ }^{8}$

De maneira geral, as alterações compatíveis com a deficiência de ferro podem ser resumidas no Quadro 3.

\begin{tabular}{ll}
\multicolumn{2}{c}{ Quadro 3. Diagnóstico laboratorial de AF } \\
\hline VCM. HCM & Reduzidos \\
RDW & Elevado \\
CHr/RetHe & Reduzidos \\
\% de hemácias hipocrômicas & Elevada \\
Contagem de reticulócitos & Reduzida em relação à anemia \\
Ferro sérico & Reduzido \\
TIBC & Elevado \\
Saturação da transferrina & Reduzida \\
Ferritina sérica & Reduzida \\
sTfR & Elevado \\
sTfR/logFerritina & Elevado \\
ZPP & Elevado \\
\hline
\end{tabular}

VCM: volume corpuscular médio; HCM: hemoglobina corpuscular média; RDW: índice de anisocitose; $\mathrm{CHr}$, RetHe: conteúdo de hemoglobina nos reticulócitos; TIBC: capacidade total de ligação do ferro à transferrina; sTfR: receptor solúvel da transferrina; ZPP: zincoprotoporfirina

No entanto, vale a pena lembrar que a instalação da deficiência de ferro é progressiva e as alterações laboratoriais têm uma dinâmica, como pode ser observado na Figura 2. Assim, na fase de depleção de estoque, a principal alteração observada é a diminuição gradativa dos níveis de ferritina sérica. $\mathrm{Na}$ fase de deficiência na eritropoese, os níveis de $\mathrm{Hb}$ estão ainda na faixa de normalidade, mas são detectados sinais de falha na hemoglobinização das células, com queda do conteúdo de $\mathrm{Hb}$ dos reticulócitos (não mostrado na figura) e 


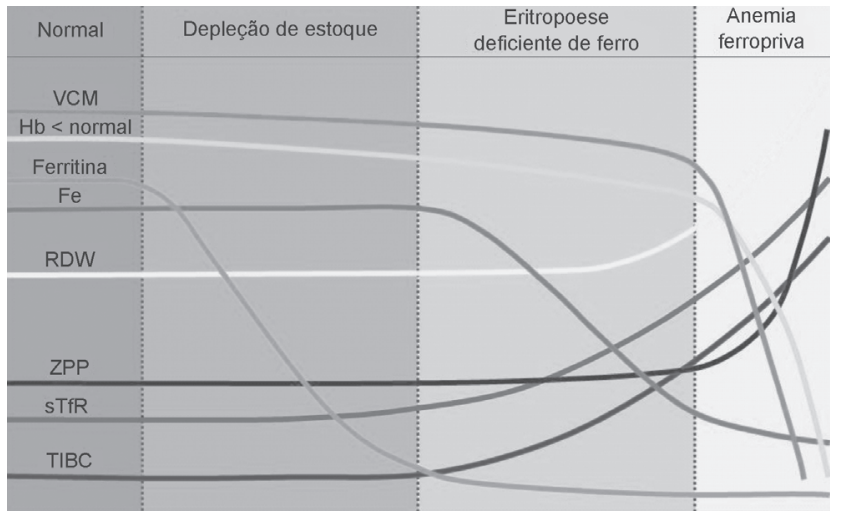

Figura 2. Evolução das alterações laboratoriais no decorrer da evolução da deprivação de ferro.

VCM; volume corpuscular médio; Hb: hemoglobina; Fe: ferro sérico; RDW: índice de anisocitose; ZPP: zincoprotoporfirina; sTfR: receptor solúvel da transferrina; TIBC: capacidade total de ligação do ferro à transferrina

elevação dos níveis de sTfR e TIBC. E, por último, as alterações relacionadas com o quadro de anemia. A anisocitose é a alteração morfológica dos eritrócitos mais precocemente evidenciada e tipicamente é acompanhada de ovalocitose. Nessa fase inicial, o HCM pode estar normal, a $\mathrm{Hb}>$ $11 \mathrm{~g} / \mathrm{dL}$ e o VCM ligeiramente reduzido $(<80 \mathrm{fl})$. Com a progressão da deficiência de ferro há um declínio concomitante da concentração de $\mathrm{Hb}$, do número de hemácias, do HCM e VCM. ${ }^{29}$

\begin{abstract}
Iron deficiency is the most common cause of anemia and, in general, the diagnosis is easily established by simple tests that are routinely available in general laboratories. The interpretation of results, however, must be carefully carried out keeping in mind the limitations and interference in each reaction. This review presents the tests that assist in the investigation of iron deficiency, with some technical aspects and comments on their interpretation. Rev. Bras. Hematol. Hemoter. 2010;32(Supl.2):22-28.
\end{abstract}

Key words: Iron deficiency anemia; laboratory findings; hypochromic anemia.

\section{Referências Bibliográficas}

1. Cook JD. Diagnosis and management of iron-deficiency anaemia. Best Pract Res Clin Haematol. 2005;18(2):319-32.

2. Lewis SM. Reference ranges and normal values. In: Lewis SM, Bain BJ, Bates I, editors. Practical Haematology. $10^{\text {th }}$ ed. London: Churchill Livingstone; 2006:11-24.

3. Lima CSP, Reis ARC, Grotto HZW, Saad STO, Costa FF. Comparison of red cell distribution width and a red cell discriminant function incorporating volume dispersion for distinguishing iron deficiency from beta thalassemia trait in patients with microcytosis. São Paulo Med J. 1996;114(5):1265-9.
4. Bain BJ. Diagnosis from the blood smear. N Engl J Med. 2005; 353(5):498-507.

5. Elghetany MT, Davey F. Distúrbios eritrocitários. In: Henry JB, editor. Diagnósticos clínicos e tratamento por métodos laboratoriais. 20 ${ }^{\mathrm{a}}$ ed. São Paulo. Manole Ltda; 2008:632.

6. Beutler E, Hoffbrand AV, Cook JD. Iron deficiency and overload. Hematology Am Soc Hematol Educ Program. 2003: $40-61$

7. Grotto HZW. Interpretação clínica do hemograma. Lopes AC, Grotto HZW eds. São Paulo. Editora Atheneu; 2009.

8. Cook JD, Baynes RD, Skikne B. Iron deficiency and the measurement of iron status. Nutr Res Rev. 1992;5(1):189-202.

9. Worwood M. Iron-deficiency anaemia and iron overload. In: Lewis SM, Bain BJ, Bates I., editors. Practical Haematology. $10^{\text {th }}$ ed. London: Churchill Livigstone; 2006:132-60.

10. Dale JC, Burritt MF, Zinsmeister AR. Diurnal variation of serum iron, iron-binding capacity, transferrin saturation, and ferritin levels. Am J Clin Pathol. 2002;117(5):802-8.

11. Hristova EM, Henry JB. Intermediários metabólicos, íons inorgânicos e marcadores bioquímicos do metabolismo ósseo. In: Henry $\mathrm{JB}$, editor. Diagnósticos clínicos e tratamento por métodos laboratoriais. 20 a ed. São Paulo. Manole Ltda; 2008:220.

12. Worwood M. Influence of disease on iron status. Proc Nutr Soc. 1997;56:409-19.

13. Worwood M. Serum transferrin receptor assays and their application. Ann Clin Biochem. 2002;39(Pt 3):221-30.

14. De Lima GAFM, Grotto HZW. Laboratory assessment of iron status and reticulocyte parameters in differential diagnosis of iron deficiency anemia and heterozygous $\beta$-thalassemia. J Bras Patol Med Lab. 2002;38(4):273-80

15. Wians FH Jr., Urban JE, Keffer JH, Kroft SH. Discriminating between iron deficiency anemia and anemia of chronic disease using traditional indices of iron status vs transferrin receptor concentration. Am J Clin Pathol. 2001;115(1):112-8.

16. Remacha AF, Sarda MP, Parellada M, Ubeda J, Mantiga R. The role of serum transferrin receptor in the diagnosis of iron deficiency. Haematologica. 1998;83(11):963-6.

17. Punnonen K, Irjala K, Rajamaki A. Serum transferrin receptor and its ratio to serum ferritin in the diagnosis of iron deficiency. Blood. 1997;89(3):1052-7.

18. Thomas C, Thomas L. Biochemical markers and hematologic indices in the diagnosis of functional iron deficiency. Clin Chem. 2002;48(7):1066-76.

19. Brugnara C. Use of reticulocyte cellular indices in the diagnosis and treatment of hematological disorders. Int J Clin Lab Res. 1998; 28(1):1-11.

20. Bartels PC, Schoorl M, Schoorl M. Hemoglobinization and functional availability of iron for erythropoiesis in case of thalassemia and iron deficiency anemia. Clin Lab. 2006;52(34):107-14

21. Swirsky D, Bain BJ. Erythrocyte and leucocyte cytochemistry leukemia classification. In: Lewis SM, Bain BJ, Bates I, editors. Practical Haematology. $9^{\text {th }}$ ed. London: Churchill Livigstone; 2001:269-95.

22. Davey FR, Hutchison RE. Hematopoese. In: Henry JB, editor. Diagnósticos clínicos e tratamento por métodos laboratoriais. $20^{\mathrm{a}}$ ed. São Paulo. Manole Ltda; 2008:220.

23. Cook JD. Clinical evaluation of iron deficiency. Semin Hematol 1982;19(1):6-18.

24. Baynes RD. Assessment of iron status. Clin Biochem. 1996; 29(3):209-15 
25. Erslev AJ. Anemia of chronic disease. In: Beutler E, Lichtman MA, Coller BS, Kipps TJ, Seligsohn U, eds. Williams Hematology. 6th ed. New York. Mc Graw Hill; 2001:481-7.

26. Chapman RW, Hussain MA, Gorman A, Laulicht M, Politis D, Flynn DM, et al. Effect of ascorbic acid deficiency on serum ferritin concentration in patients with beta-thalassaemia major and iron overload. J Clin Pathol. 1982;35(5):487-91.

27. Girelli D, Olivieri O, De Franceschi L, Corrocher R, Bergamaschi G, Cazzola M. A linkage between hereditary hyperferritinaemia not related to iron overload and autosomal dominant congenital cataract. Br J Haematol. 1995;90(4):931-4.

28. Beaumont C, Leneuve P, Devaux I, Scoazec JY, Berthier M, Loiseau $\mathrm{MN}$, et al. Mutation in the iron responsive element of the $\mathrm{L}$ ferritin mRNA in a family with dominant hyperferritinemia and cataract. Nat Genet. 1995;11(4):444-6.

29. Fairbanks VF, Beutler E. Iron deficiency. In: Beutler E, Lichtman MA, Coller BS, Kipps TJ, Seligsohn U, eds. Williams Hematology. 6th ed. New York. Mc Graw Hill; 2001:447-470.

O tema foi sugerido e avaliado pelo coeditor deste fascículo educativo, Rodolfo Delfini Cançado, e pelo board interno da RBHH, e publicado após a concordância do editor, Milton Artur Ruiz.

Conflito de interesse: sem conflito de interesse

Recebido: $15 / 12 / 2009$

Aceito: 15/01/2010 